\title{
Survey on Dermatophytosis in Iraqi camels
}

\author{
M. H. Hussain
}

Col. of Vet. Med./ Al-Qadissiya Univ.

\section{Abstract}

This survey aimed to answer a question has applied in the clinics "what are the fungal skin affections in Iraqi camels?". The survey, in three provinces; Al-Qadissiya, Al- Najaf \& AlMuthanna; has identified three Dermatophytes "Trichophyton verrucosum in 58\%, Microsporum canis in $42 \%$ \& Epidermophyton fluccosum in $22 \%$ " \& four non-dermatophytes "Penicillium brevicompactum in $31.6 \%$, Ulocladium chartarum in $22.8 \%$, Aspergillus fumigates in $22.8 \%$ \& Scopulariopsis bainier in 22.8\%" in 112 camels. Dermatophytosis has diagnosed in $65.2 \%$ in camels less than 5 years old, $34.8 \%$ in camels 5-10 years old \& no cases were diagnosed in camels more than 10 years old.

\section{Introduction}

Dermatophytosis is an infection of keratinized tissue (skin, hairs, and claws) by one of the three genera of fungi collectively called dermatophytes; Trichophyton, Microsporum, and Epidermophyton. These pathogenic fungi are found worldwide, and all domestic animals are susceptible. Various fungal species can produce infection of the epidermis, of which the species causing dermatophytosis (ringworm) which are the commonest in camels. Dermatophytosis is a common skin disease in old world camels (OWC) under 3 years of age with a peak incidence age of between 3 to 12 months. In new world camels (NWC) it is, however, a very rare disease (5) and only $T$. verrucosum and $T$. mentagrophytes have been isolated from NWC so far. In most circumstances, dermatophytes grow only in dead, keratinized tissue; advancing infection halts upon reaching live cells or inflamed tissue (11).

\section{Materials and Methods}

1- Potassium hydroxide sol. $10 \%$

2- Sodium hydroxide sol. $10 \%$

3- Lacto phenol cotton blue stain

4- Yeast extract

5- Thiamine

6- Chloramphenicol

7- Amikacin

8- Sabouraud dextrose agar

Direct microscopic examination of hairs or skin scrapings might reveal characteristic hyphae and/or arthrospores. However, fungal culture is the most effective and specific means of diagnosis, although growth usually requires 10 to 14 days of incubation (8). Microsporum spp. and Trichophyton spp. as well as other fungi should be cultured on Sabouraud dextrose agar and on Mycoline agar slide (bioMandieux) and incubated for 10 to 14 days at $27^{\circ} \mathrm{C}$. Definite diagnosis and species identification requires removal of hyphae and macroconidiae from the surface of the colony with acetate tape and microscopic examination with Lactophenol Cotton Blue (LPCB) stain. Culture on Mycoline agar slide is especially helpful when saprophytic contamination is expected (11).

Modified Sabouraud Dextrose Agar (SDA) was prepared as below:

$\begin{array}{ll}65 \mathrm{gm} & \text { Sabouraud dextrose agar } \\ 5 \mathrm{gm} & \text { Yeast extract } \\ 0.05 \mathrm{gm} & \text { Chloramphenicol } \\ 0.5 \mathrm{gm} & \text { Cycloheximide } \\ 0.01 \mathrm{gm} & \text { Thiamin } \\ 1000 \mathrm{ml} & \text { Distilled water }\end{array}$

Lactophenole cotton blue stain was prepared in the laboratory using:-

$20 \mathrm{ml} \quad$ Lactic acid

$20 \mathrm{gm} \quad$ Phenol crystals

$40 \mathrm{ml} \quad$ Glycerin

$0.05 \mathrm{gm} \quad$ Anelin blue

$20 \mathrm{ml}$ Dist. water 
Phenol crystals to be dissolved in lactic acid and water by slow heating, Anelin blue was added and mixed well (1).

Three governorates were involved in this research Al-Qadissiya, Al-Najaf and AlMuthanna, samples collected from the slaughter houses, sale yards and the herds found in several locations randomly. The research began on December 2008 and finished on June 2009. 2412 Iraqi dromedaries were examined regardless to location, age, sex and breed, from which 482 camels were suffering skin affections. Camels were inspected to find infections with fungal lesions. Skin scrapings were collected after washing the lesion with $70 \%$ ethanol to be transported to the laboratory by using screw cab containers. (10).

Steps of identification include:-

1- Clinical signs : - lesions were prescribed according to the site, shape, color,

hair coat and any other signs. The general description of camels including; temperature, respiratory rate, pulse rate, mucous membrane, appetite and ruminating and other features.

2- Scrapings were taken to be cultured on the Modified Sabouraud Dextrose Agar SDA that was prepared in the laboratory. For purification, multiple cultures were done to obtain clear and pure colonies without contaminations. Media were incubated at $28^{\circ} \mathrm{C}$ for up to 2 weeks according to the growth appearance. Each type of dermatophytes were examined microscopically by making slide smears from the pure colonies and stained with Lactophenole Cotton Blue Stain LCB. Different charachterestic features confirmed the diagnosis which depends on the shape of the colony, the microscopic appearance and microscopic examinations of the hides.

\section{Results}

The survey has found 112 camels infected with dermatophytosis in different sexes but in less than 10 years old and most commonly in camels less than 5 years old with $65.2 \%$ and $34.8 \%$ in camels in $5-10$ years old. It seems that camels less than 5 years old are more susceptible to fungal infection with dermatophtes. Both sexes are likely to have the same percentage of infection, as in table (2). Three dermatophytes and four non-dermatophytes have been diagnosed in the laboratory after

sampling skin scrapings from the suspected camels as illustrated in table (1), the diagnosis depends on the duration of growth, features of the colonies and the microscopic appearance after preparing the slides stained with the lactophonole cotton blue which is the most effective and specific means for fungal diagnosis (6) and (7). As showed in table (1), seven species of fungi were described according to the duration of growth in the colonies obtained after culture.

Table (1): Dermatophytes were diagnosed in the study.

\begin{tabular}{|l|l|c|}
\hline \multicolumn{2}{|c|}{ Dermatomycosis } & $\begin{array}{c}\text { duration of } \\
\text { growth (day) }\end{array}$ \\
\hline \multirow{4}{*}{ Dermatophytes } & Trichophyton verrucosum & $10-14$ \\
\cline { 2 - 3 } Non-dermatophytes & Microsporum canis & $8-12$ \\
\cline { 2 - 3 } & Epidermophton fluccosum & $4-7$ \\
\hline & Penicillium brevicompactum & $2-5$ \\
\cline { 2 - 3 } & Ulocladium chartarum & $3-5$ \\
\cline { 2 - 3 } & Aspergillus fumigates & $2-4$ \\
\cline { 2 - 3 } & Scopulariopsis bainier & $3-6$ \\
\hline
\end{tabular}


Trichophyton verrucosum was the most common case 58\% accompanied with Epidermatophyton fluccosum in 9 cases, the lesions were multifocal on the neck, legs, head , shoulders, chest, and perineum respectively in which, as in fig (1), graywhite crusts raised slightly on the skin in circles within $1-3 \mathrm{~cm}$ in diameter with moist surface beneath in the early stage loosing hair, when the lesion over growth the surface become hairless, gray, dry and the crusts detached and the circles conjoin to present the whole site on the infected area. It seems to be due to the slow spread of lesions in the herd and their self-limiting in about 25-40 days with normal skin finally. Microsporum canis have the same clinical features, but the lesions spreaded mostly in the perineum and they looked irregular shapes and the spots unite soon after with rapid hair loose, $E$. fluccosum had diagnosed in 16 camels accompanied with $M$. canis on the same individuals. No systemic reactions to be observed on the camels having ring worm, (36.3 \pm 0.03$) \mathrm{C}^{\mathrm{o}}$ in temperature, $(15 \pm 0.5)$ respiratory rate, $(45 \pm 1.5)$ pulse rate, pink mucous membrane, hair loss, no lameness when the leg infected, normal appetite and ruminating and itching seems to be rare . Accidental respiratory disorders or diarrhea have seen in several cases.

Table (2): Numbers of infected camels with cutaneous fungi according to the location, age and

\begin{tabular}{|c|c|c|c|c|c|c|c|c|}
\hline \multicolumn{9}{|c|}{ sex } \\
\hline \multirow{2}{*}{\multicolumn{2}{|c|}{ Locations }} & \multirow{3}{*}{$\begin{array}{c}\text { Infected } \\
\text { camels } \\
19\end{array}$} & \multicolumn{2}{|c|}{$\sim 5$ years } & \multicolumn{2}{|c|}{$5-10$ years } & \multicolumn{2}{|c|}{ 10 years } \\
\hline & & & male & female & male & female & male & female \\
\hline \multirow{6}{*}{$\begin{array}{c}\text { Al- } \\
\text { Qadissyia }\end{array}$} & Slaughter house & & 1 & 10 & 5 & 3 & 0 & 0 \\
\hline & $\begin{array}{l}\text { Al-Hamza Al- } \\
\text { Shargy }\end{array}$ & 6 & 3 & 1 & 0 & 2 & 0 & 0 \\
\hline & Al-Daghara & 0 & 0 & 0 & 0 & 0 & 0 & 0 \\
\hline & Aal-Bdeer & 11 & 2 & 5 & 2 & 2 & 0 & 0 \\
\hline & Al-Shaf'ya & 0 & 0 & 0 & 0 & 0 & 0 & 0 \\
\hline & Al-Shenafeya & 16 & 3 & 8 & 1 & 4 & 0 & 0 \\
\hline \multirow{2}{*}{ Al-Najaf } & Slaughter house & 19 & 11 & 2 & 3 & 3 & 0 & 0 \\
\hline & Sale yard & 22 & 9 & 4 & 6 & 3 & 0 & 0 \\
\hline \multirow{3}{*}{$\begin{array}{c}\text { Al- } \\
\text { Muthanna }\end{array}$} & Slaughter house & 2 & 2 & 0 & 0 & 0 & 0 & 0 \\
\hline & Sale yard & 0 & 0 & 0 & 0 & 0 & 0 & 0 \\
\hline & Herds & 17 & 3 & 9 & 2 & 3 & 0 & 0 \\
\hline \multicolumn{2}{|l|}{ Total } & 112 & 34 & 39 & 19 & 20 & 0 & 0 \\
\hline \multicolumn{2}{|l|}{ Percentage } & & 30.4 & 34.8 & 17 & 17.8 & 0 & 0 \\
\hline \multicolumn{2}{|l|}{ Total } & & \multicolumn{2}{|c|}{73} & \multicolumn{2}{|c|}{39} & \multicolumn{2}{|c|}{0} \\
\hline \multicolumn{2}{|l|}{ Percentage } & & \multicolumn{2}{|c|}{65.2} & \multicolumn{2}{|c|}{34.8} & \multicolumn{2}{|c|}{0} \\
\hline
\end{tabular}




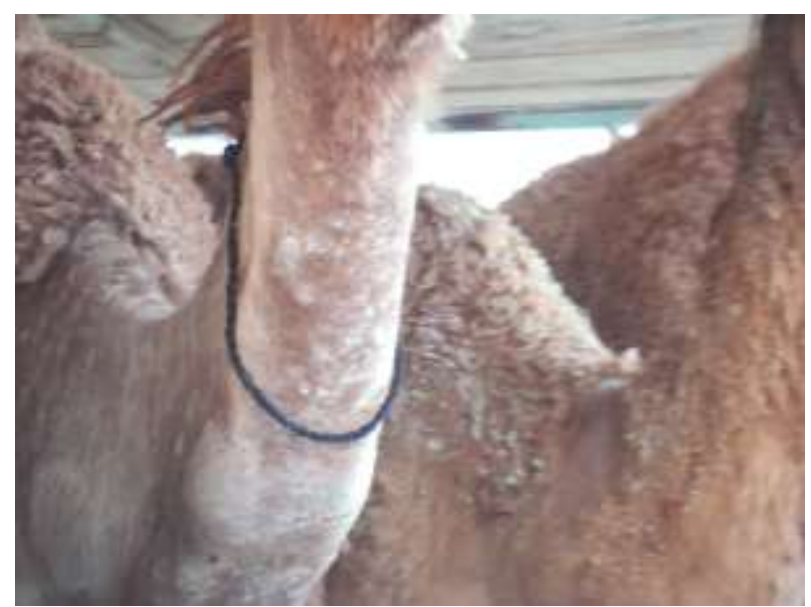

Fig (1): Trichophyton verrucosum (ring worm) in 3.5 years camel, circular lesions on the neck.

Colony of the T. verrucosum on the modified SDA slowly appears heaped, white powdery surface at the first few days; within incubation the center becomes brown illustrated in fig (2). Microscopically, slide smear stained with lactophenol cotton blue shows, as in fig (3), thin irregular mycelium with chlamydospores that form heavy chains. Macroconidia are extremely rare, three to five celled with thin and small walls vary considerably in size and shape.

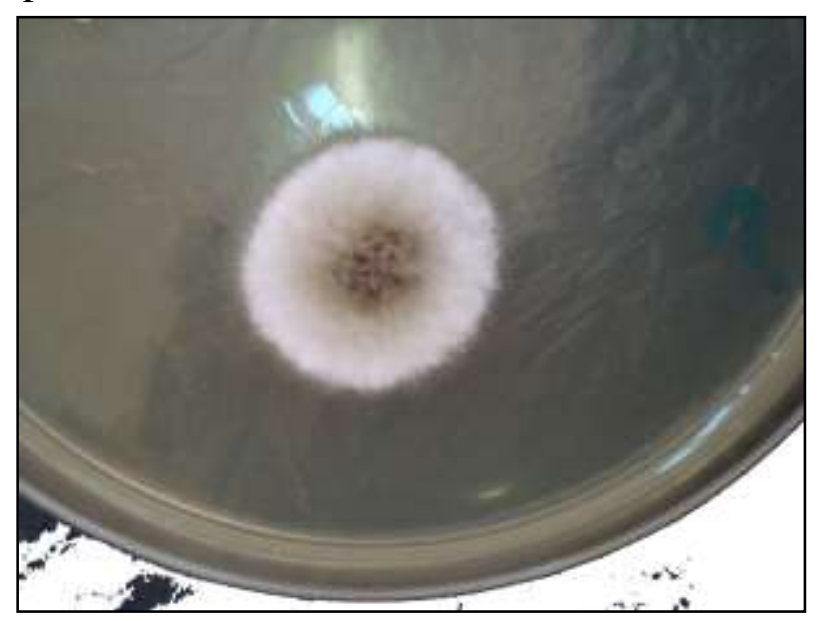

Fig (2): Colony of the T. verrucosum on the modified SDA.

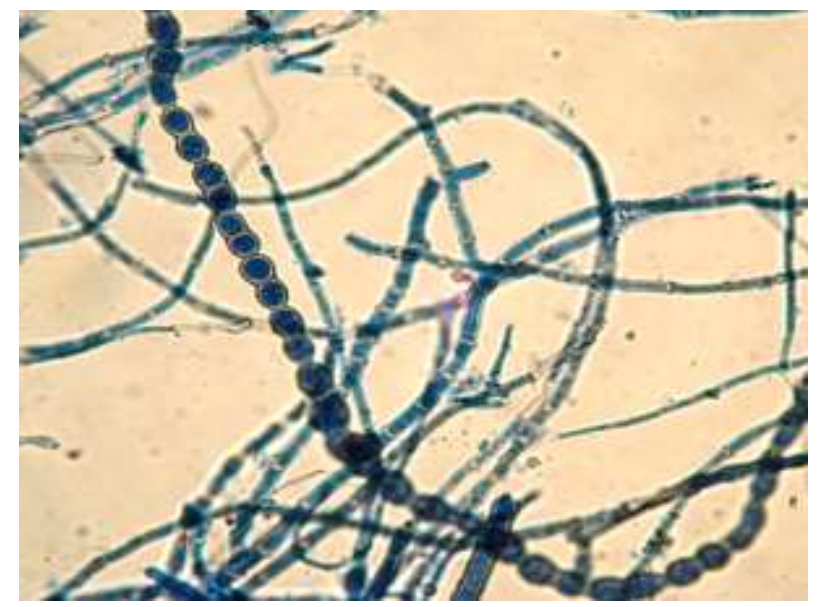

Fig (3): Microscopic appearance of T. verrucosum.X100 


\section{Discussion}

Camels' dermatophytosis had been reported in Iraq by Al-Ani, et al., 1995 through a study found out infections with Trichophyton schoenleinii. 13 nondermatophytes reported in Al-Basrah by Abdul-Aziz (2000), only A.fumigatus was corporate and the other types were different. Differences may belong to the variance between Al-Qadissiya and Al-Basrah in several factors; type of the soil, climatic features, temperature and humidity, regarding to the fact that several nondermatophytes are soil-borne fungi while others may be food-borne fungi. Consequently, there will be some differences in the types of fungi that suspended to animals' skin. Absence of infections in camels older than 10 years may reveals the formation of immunity against this cutaneous pathogen, but also it has reported that ring worm is more common in camels less than 5 years old. Other types of dermatophytes had reported in the world, but it's obvious, that $T$. verrucosum is the most vulgar dermatophyte since it has reported by Curasson in 1947. Diagnosis was made by the help of Introduction of food-borne fungi (9) and the Introducing mycology by examples, texts with pictures for diagnosis of fungi, a special help from Prof. Dr. M. K. Faraj, Dept of Microbiology/ College of Veterinary Medicine, Baghdad University.

\section{References}

Pathogenic Fungi. Your Book Medical Publishers. Chicage. 268.

7- Midgley, G.; Clayton, Y. and Hay, R. J. (1997). Diagnosis in color medical mycology Mosby Wolfe, an imprint of Mosby international. Spain. 155.

8- Radostits, O.M.; Gay, C.C.; Hinchcliff, K.W.; \& Constable, P.D. (2007). Veterinary Medicine, A textbook of the diseases of cattle, horses, sheep, pigs \& goats. $10^{\text {th }}$ ed. Elsevier Saunders, Spain.

9- Rebert, A.S.; Ellen, S.H.; \& Connie, A.N.(1984). Itroduction of foodborne fungi. $2^{\text {nd }}$, Central bureau voor schimmel cultures. Institute of the royal Netherl\&s, Academy of art \& science.

10- Songer, J.G.; \& Post, K.W.( 2005). Veterinary Microbiology, Bacterial \& Fungal agents of animal diseases, chapter four; the genus Staphylococcus. Elsevier Saunders, china.

11- Wernery, U.; \& Kaaden, O.R. (2002). Infectious diseases in camelids, $2^{\text {nd }}$ revised \& enlarged edition. Blackwell Wissenschafts-Verlag

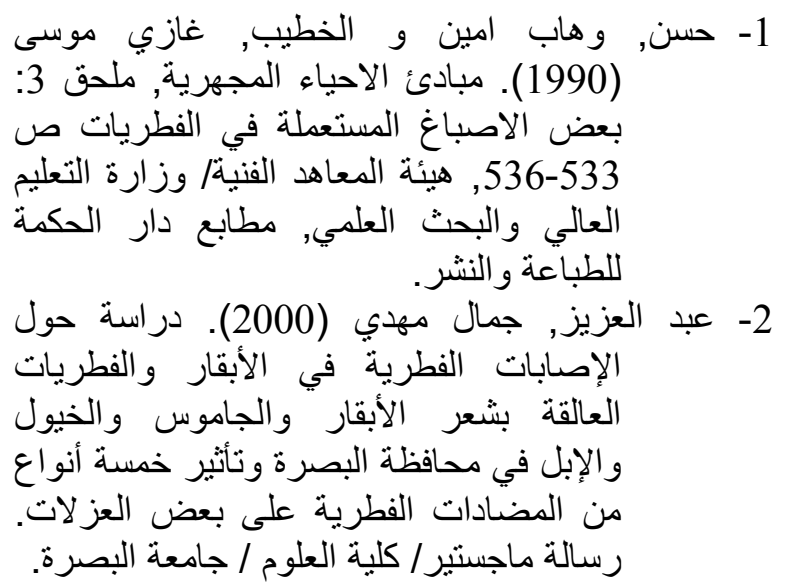

3- Al-Ani, F. K.; Al-Bassam, L.S. \& AlSalahi, K.A. (1995). Epidemiological study of dermatomycosis due to Trichophyton schoenleinii in camels in Iraq. Bull. Anim. Hlth. Prod. Afi. 43: 87-92.

4- Curasson, G. (1947). Le chameau et ses maladies. Vigot Fr\&es, Editeurs: pp. 86-88.

5- Fowler, M.E. (1998).Medicine \& surgery of South American Camelids. Iowa State University Press, Ames. USA.

6- Frey, D.; Oldfield, R. J. and Bridger, R. C. (1979). A Color Atlas of

12- GmbH Kurfiirstendamm 57,10707 Berlin 


\section{مسح ميداني عن الفطريات الجلدية في الإبل العراقية

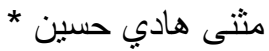 كلية الطب البيطري/ جامعة القين القادية \\ الخلاصة}

إجابة على السؤال الذي طالما يطرح في العيادات والمستشفيات البيطرية "ما هي الإصابات الجلدية الفطرية في الإبل

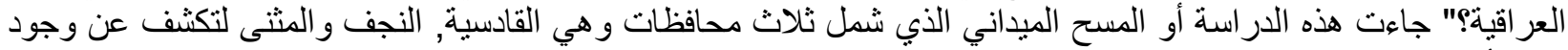

Trichophyton verrucosum in $58 \%$. ثلاث أنواع من الفطريات الجلدية المررضة وهي:

Microsporum canis in $42 \%$.

Epidermophyton fluccosum in $22 \%$.

Penicillium brevicompactum in $31.6 \%$.

بالإضـافة إلى أربع أنواع من الفطريات الجلدية غير الممرضة وهي:

Ulocladium chartarum in $22.8 \%$.

Aspergillus fumigates in $22.8 \%$.

Scopulariopsis bainier in $22.8 \%$.

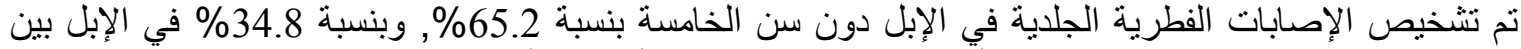

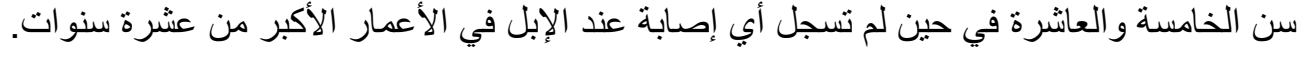

